\title{
Natural Dyeing Materials from Opuntia humifusa for Hair
}

Ju-Sub Kim ${ }^{1}$, Se-Eun You ${ }^{2 *}$

${ }^{1}$ Department of Cosmetology, Sangji Youngseo College, Wonju-si, Gangwon-do, Korea

${ }^{2}$ Department of Beauty Hair Style, Yeoju College, Yeoju-si, Gyeondgi-do, Korea

\author{
*Corresponding author: Se-Eun You, \\ Department of Beauty Hair Stylist, Yeoju \\ College, 338 Saison-ro, Yeoju-si, Gyeondgi- \\ do 12652 , Korea \\ Tel.: +82 318805555 \\ Fax: +82318835113 \\ Email: yhy7438@hanmail.net
}

Received January 14, 2019

Revised February 12, 2019

Accepted February 13, 2019

Published March 30, 2019

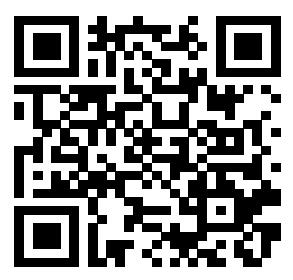

\begin{abstract}
Purpose: A common way to enhance beauty is using hair coloring. This study sought to develop a natural hair coloring ingredient that could reduce hair damage. Methods: First, Opuntia humifusa powder, or eastern prickly pear cactus powder, was applied to samples of virgin hair and three bleached hair levels (levels 7, 9, and 11), after which the samples were heated either for $10 \mathrm{~min}$ or $20 \mathrm{~min}$ and then washed. To assess the dyeing effectiveness, the samples' $L^{*}, a^{*}, b^{*}$, and $C^{*}$ decoloring values were compared, and to analyze the hair texture, tensile strength was measured. Results: It was found that the $L^{*}, a^{*}, b^{*}$, and $C^{*}$ values and the $K$ / $S$ values were greater in the hair samples that had been heated for $20 \mathrm{~min}$, and the tensile strength of samples coated Opuntia humifusa was higher than that of bleached hair samples. No color fading was observed when the samples were measured 5 days after the dyeing. After being dyed with the Opuntia humifusa, an increase in the $L^{*}, a^{*}, b^{*}$, and $C^{*}$ values and an improvement in tensile strength and hair texture was observed. Conclusion: Therefore, it appears that Opuntia humifusa could be an effective natural coloring ingredient that could improve hair strength and texture.
\end{abstract}

Keywords: Opuntia humifusa, Hair, Dye power, Change, Cuticle

\section{Introduction}

바쁜 현대 사회에서 자신의 외모를 꾸미는 일 역시 중요한 일이 고, 그 외모를 유지 관리하는 일도 중요한 일이다. 외모를 아름답 게 꾸미는 방법에는 헤어스타일, 메이크업, 패션 등이 있을 수 있 다. 그 여러 가지 방법 중에 헤어스타일로 자신의 외모를 아름답 게 꾸미는 방법에도 여러 가지 방법인 염색, 퍼머넌트 웨이브, 커 트 등이 있다(Kim, 2017; Yoo \& Choi, 2017). 이러한 자신의 개 성을 표현 하려는 경향이 증가되고 있는 시점에서 컬러에 대한 다양한 모발 염색은 급속히 대중화 보편화 되고 있다. 미용실에 서 사용되고 있는 대부분의 염모제는 합성원료로 제조된 염모제 로, 시술시간을 단축시키고 색상을 잘 표현 할 수 있고, 사용하거 나 보관이 쉬워 많이 사용되고 있다(Kim, 1992). 그러나 많은 염 색 시술 시 두피의 부작용 및 모발에 손상을 야기 시키기도 한다 (Jeong et al., 2012). 염모제는 헤나와 같이 천연염료와 화학성 분인 합성 염모제로 크게 구분할 수 있다(Kim et al., 2006). 두피 와 모발에 손상을 야기하는 것을 방지하기 위해 두피의 염증 유발
을 적게 하는 천연물질 연구가 이루어지고 있다(Kim, 2014a). 또 한 여러 가지 천연성분인 우엉뿌리 추출물이 두피에 미치는 영향, 고량색소의 염색력 연구, 남천잎 추출물의 생리활성 연구, 소목에 의한 모발의 물리적 성상변화, 천마 추출물이 모발의 화학적 반 복 시술에 미치는 효과 등 연구가 선행 되었다(Choi, 2015; Kim \& Choe, 2010; Kim \& Ko, 2014; Lee et al., 2015; Moon \& $\mathrm{Kim}, 2015)$. 천연염색 등 천연재료를 원료로 사용하는 다양한 제 품수요가 건강을 생각하는 트랜드의 변화와 같이 수요가 커지고 있다(Kim \& Kwon, 2008). 천연염색에 사용되는 원료로 적색계 열에는 홍화, 소목, 코치닐, 꼭두서니 등이 있다(Cho, 2000). 천 연염색을 시술하기 위해서는 천연성분이 첨가된 염모제를 제조하 거나, 천연성분 자체를 모발에 도포하여 염색을 표현한다. 이러한 천연성분을 이용한 염색력 연구로 백련초 성분자체를 모발에 도포 하여 백련초가 천연염모제 성분으로서의 상용화 가치가 있는지 연 구하고자 한다.

산업화와 기술의 눈부신 발달은 염색 산업적 측면에서 볼 때 수 없이 많은 합성염료를 개발하였으며 이를 이용하여 다양한 색상과 
염색 등의 편리함을 제공하였다. 그러나 염료의 개발은 환경오염 과 발암성 물질 배출 등의 문제를 야기하여 근래에는 천연염료에 대한 관심이 높아지고 있다(Bai, 2005).

상업적인 염색과 합성염료가 광범위하게 사용되고 있음에도 불 구하고 천연염료의 사용에 대한 관심은 지속적으로 증가하고 있 다. 천연염료의 생산 및 시장, 염색의 안전성 및 인체 적합성 등에 대한 연구가 지속적으로 필요하다. 천연염료가 합성염료를 모두 다 대신할 수는 없지만 상당부분 경제적으로 우수한 점이 있으며, 환경문제를 고려하면 천연염색의 산업화 경쟁력이 있다고 생각한 다.

백련초(Opuntia humifusa)는 부채 선인장과에 속하며 형태에 따라 구분하면 부채꼴 선인장류로 구분된다. 사람 손바닥 모양을 닮았고, 매년 4-5월경에 꽃이 피고 11-12월경에 자주색 열매가 익는다. 우리나라에서는 제주도, 남해안 등지에서 자라고, 키가 작고 생명력이 강하며 재배하기가 용이하다(Choi \& Jung, 2017; Kuti \& Galloway, 1994). 외국뿐만 아니라 국내에서도 민간요법 으로 사용되고 있으며 발효된 백년초 발효물의 피부생리활성 평 가 연구, 백련초 추출물 첨가 김치의 품질특성 연구가 선행 되었 다(Lee \& Rho, 2012; Kim \& Do, 2017). 이러한 백련초에 관 한 연구가 다양하게 이루어지고 있지만 모발과 백련초와의 상관관 계 연구는 백년초 추출물을 처방한 미스트의 펌 전처리 효과 연구 (Kim, 2014b)가 있으나 미비한 실정이고, 백련초 성분과 모발의 염색력에 관한 연구가 이루어지지 않고 있다.

따라서 본 연구는 다방면에 사용되는 백련초를 천연염색의 원 료로 사용가능한지를 알아보고자 하여 백련초 분말색소를 액체로 중탕하여 모발시료에 도포한 후 시료의 염색력과 물빠짐을 측정하 여 천연색소의 염색효과를 알아보고, 천연색소 도포로 인한 모발 의 성질 변화를 알아보기 위해 인장강도 실험으로 모질의 변화를 알아보고자 하였다.

\section{Methods}

\section{1. 실험재료}

1) 시료모발

실험을 위하여 시료로 사용된 모발은 최근 2 년 동안 약물복용 과 화학적 시술을 하지 않은 여성의 모발을 후두부에서 두피 $3 \mathrm{~cm}$ 지점을 기준으로 $20 \mathrm{~cm}$ 로 채취하여 $1 \mathrm{~g}$ 씩 모(hair) 다발을 만들고 $\mathrm{pH} 7.0$ 의 중성 샴푸로 세척, 자연건조 하여 사용하였다. 이후 백 련초의 염색성을 확인하기 위하여 건강모와 이 건강모발에 탈색제 제1제(ammonium persulfate, potassium persulfate, sodium metasilicate, magnesium, sodium carboxymethyl cellulose) (Suanhj, Korea) $3 \mathrm{mg}$ 과 제2제(6\%의 과산화수소를 주성분으 로 water, etidronic acid, phosphoric acid, sodium phosphate

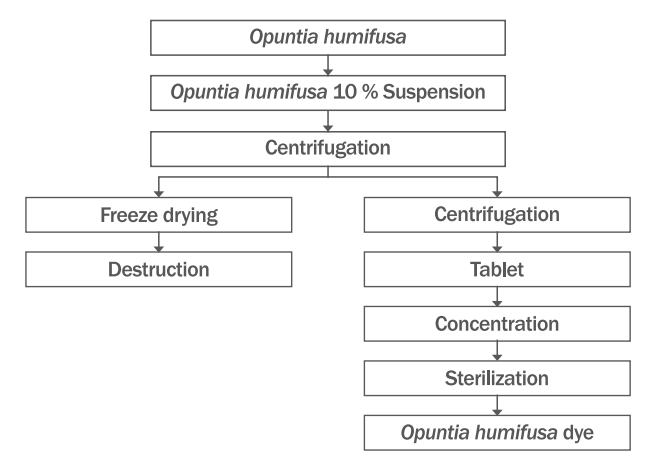

Figure 1. Gardenia pigment extraction method.

Cactus pear powder was extracted using a general extraction method with water and ethanol.

dibasic, cetyl alcohol로 구성된 제품) (Suanhj, Korea) $3 \mathrm{~mL}$ 비율로 혼합하여 도포하고 $30 \mathrm{~min}$ 방치 후 1 회 탈색하여 명도 7 레벨로 시료를 제작하고, 2 회 탈색하여 명도 9 레벨로, 3 회 탈색 하여 명도 11레벨로 제작하여 대조군(control group)으로 하였 다. 실험에 사용된 모발 시료의 level 측정기(level scale, Wella, Germany) 사용하였으며 level 측정은 미용 현장에서 $10 \mathrm{yr}$ 이상 근무한 전문가 6 인이 측정하였다. 측정된 시료를 실험에 사용하 였다. 이 시료에 백련초로 염색한 모발시료를 실험군(experiment group)으로 하였다.

2) 백련초 분말색소

본 실험에 사용할 백련초 분말색소는 제주도 농장에서 백련초 열매를 구입하여 사용하였다. 백련초 열매에서 분말색소를 추출 하기 위해 용매는 물, 에탄올을 사용하였으며, 동결 건조한 줄기 부분을 사용하여 40 메쉬로 분쇄 후 수분함량을 $10 \%$ 이하로 건 조하고 $4^{\circ} \mathrm{C}$ 에서 $10 \mathrm{~h}$ 이상 추출한 원료를 사용하였고 추출법은 Figure 1 과 같다.

\section{3) 측정기기 및 측정방법}

(1) 백련초 염색모의 표면색상 $\left(L^{*}, a^{*}, b^{*}\right)$ 측정

방치 시간 별로 백련초 색소로 염색한 염색모와 염색을 하지 않 은 대조군 모발 시료의 염색성과 모발 표면색상의 변화를 알아보 고자 색차계(sphere spectrophotometer, SP60; X-Rite, USA) 를 이용하여 CIELAB 표색계의 색상 값인 명도지수 $\mathrm{L}^{*}$ 과 색좌 표 지수인 $a^{*}$ 와 $b^{*}$ 값을 측정하였다. 이때 광원과 광측 조건은 $\mathrm{D} 65 / 10^{\circ}$ 의 조건이었다.

$\mathrm{L}^{*}$ : CIELAB 표색계의 white-black축에서의 명도지수

$\mathrm{a}^{*}$ : CIELAB 표색계의 red-green 축에서의 채도지수

$\mathrm{b}^{*}$ : CIELAB 표색계의 yellow-blue 축에서의 채도지수 


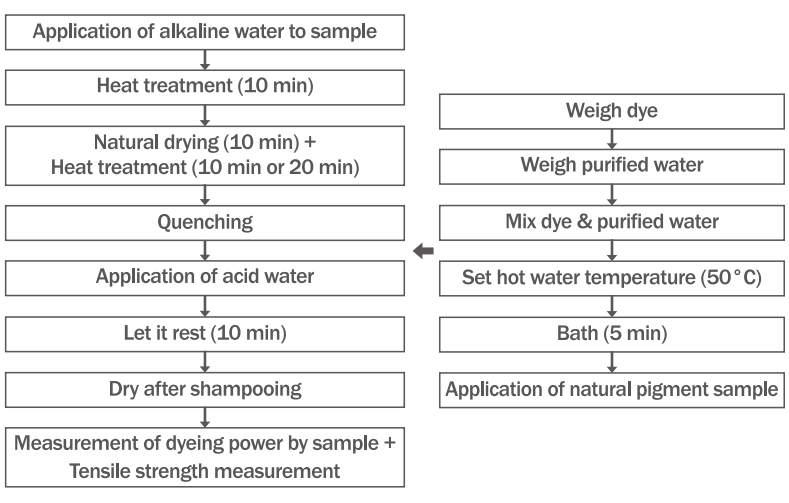

Figure 2. Experimental process.

Cactus pear powder in boiling water was applied to each sample. After natural drying for $10 \mathrm{~min}$ and heat treatment either for 10 or $20 \mathrm{~min}$, samples were washed and measured.

\section{(2) 백련초 염색모의 $C^{*}$ 측정}

방치 시간 별로 백련초 색소로 염색한 염색모와 염색을 하지 않 은 대조군 모발 시료의 염색성과 모발 표면색상의 변화를 알아보 고자 색차계(sphere spectrophotometer, SP60)를 이용하여 채 도를 측정하였다.

\section{(3) 백련초 염색모의 염착농도(K/S) 측정}

색차계(sphere spectrophotometer, SP60)로 방치 시간 별 백 련초 염색모 시료의 최대 흡광 $\left(\lambda_{\max }=750 \mathrm{~nm}\right)$ 에서 염색모의 염착 농도 $(\mathrm{K} / \mathrm{S})$ 를 산출하였다.

\section{(4) 백련초 염색모의 물빠짐 측정}

물빠짐 측정방법은 spectrophotometer (Cary 300UV; Agilent, USA)기기를 이용하여 백련초로 염색된 시험군을 일자별 로 spectrophotometer를 이용하여 $660 \mathrm{~nm}$ 에서 추출된 용액의 optical density (O.D.)값을 측정하였다. 측정기간은 5 일 동안 24 $\mathrm{h}$ 주기로 측정하였다.
(5) 백련초 염색모의 인장강도 측정

방치 시간 별로 백련초 색소로 염색한 염색모와 염색을 하지 않은 대조군 모발 시료의 인장강도 측정기기는 만능재로시험기 (No.4301; Instron, USA)로 인장시험을 실시하였다. 인장시험의 측정은 섬유단사를 측정하는 한국산업규격 섬유의 인장강도 및 신 도의 시험방법(KS K0323)에 준하여 실시하였다. 측정값의 신뢰 성을 위하여 측정값 중 제일 높은 값과 제일 낮은 값을 제외한 남 은 측정값의 평균값을 구하였다.

\section{4) 실험방법}

탈색 시술한 시료레벨 7레벨, 9레벨, 11 레벨의 시료를 제작하 였다. 사용한 천연 백련초 색소는 분말로 추출되어 있어 염색도포 가 용이 하도록 중탕으로 만들어 각각의 시료에 도포하여 시료 레 벨 별로 도포한 후 자연건조 $10 \mathrm{~min}$, 열처리 $10 \mathrm{~min}$, 열처리 20 $\min$ 후에 세척하여 측정하였다. 아래의 Figure 2 와 같은 방법으 로 실험을 하였다.

\section{5) 염색 도포방법}

염색력의 차이는 색소 함량의 차이, 자연방치시간. 열처리 시 간, 시술자의 숙련도 등에 따라서 염착력의 차이가 다를 수 있기 때문에 최대한 오차를 줄이기 위해 시술자는 각 단계별로 동일인 이 시술을 하였다. 염색도포 방법은 각 제조된 시료에 중탕한 색 소 $10 \mathrm{~g}$ 을 탈색된 각각의 레벨 시료에 도포하였다. 염색력을 향상 시키기 위한 조건 중 열과, 방치시간의 관계를 알기 위해 각 성분 함량 별로 도포 된 전체 염색시료를 자연건조 $10 \mathrm{~min}$ 하고 열처 리 시간을 $10 \mathrm{~min}, 20 \mathrm{~min}$ 으로 방치시간을 구분하였다. 방치한 후 흐르는 물에 염색소가 빠지지 않을 때까지 세척하였다. 각 시 료 표기 방법은 Table 1 과 같다.

\section{Results and Discussion}

\section{1. 백련초 염색모의 가온 처리에 따른 염색성}

Table 1. Expression method for samples

\begin{tabular}{|c|c|}
\hline Sample & Content \\
\hline Opuntia humifusa 10-virgin hair & Treatment of virgin hair sample with a 10 min application of Opuntia humifusa pigment \\
\hline Opuntia humifusa 10-7 level & Treatment of level-7 sample with Opuntia humifusaa dye and 10 min heat treatment \\
\hline Opuntia humifusa $10-9$ level & Treatment of level-9 sample with Opuntia humifusa dye and 10 min heat treatment \\
\hline Opuntia humifusa 10-11 level & Treatment of level-11 sample with Opuntia humifusa dye and 10 min heat treatment \\
\hline Opuntia humifusa 20-virgin hair & Application of Opuntia humifusa pigment to virgin hair sample for $20 \mathrm{~min}$. \\
\hline Opuntia humifusa 20-7 level & Treatment of level-7 sample with Opuntia humifusa dye and 20 min heat treatment \\
\hline Opuntia humifusa 20-9 level & Treatment of level-9 sample with Opuntia humifusa dye and 20 min heat treatment \\
\hline Opuntia humifusa 20-11 level & Treatment of level-11 sample with Opuntia humifusa dye and 20 min heat treatment \\
\hline
\end{tabular}


모발 손상을 줄이기 위한 방법으로 천연 염모제의 연구 개발이 꾸준히 이루어지고 있다. 천연성분인 백련초 분말색소로 모발시 료에 도포하여 열처리에 따른 염색성을 알아보고자 연구하여 다 음과 같은 결과를 얻을 수 있었다.

1) 백련초 염색모의 $L^{*}$ 측정

백련초 분말색소를 사용하여 $10 \mathrm{~min}$ 와 $20 \mathrm{~min}$ 열처리한 모발 의 표면색상 분석 결과 L*값은 Table 2 과 같다.

$\mathrm{L}^{*}$ 은 밝기인 명도(lightness)를 표현하는 수치로 0에서 100사 이의 수치로 표시한다. 이때 0 은 black을 나타내고, 100 은 white 를 나타낸다. 백련초를 도포하여 $10 \mathrm{~min}$ 열처리 하고 염색한 모 발의 L*값은 탈색모와 비교하여 각각의 $7,9,11$ 레벨의 모발에 서 모두 L'값은 감소하는 것을 확인 할 수 있다. 그러나 $7,9,11$ 레벨을 비교 시에는 레벨이 증가할수록 $\mathrm{L}^{*}$ 값이 증가함을 확인 할 수 있다.

이 결과는 모발의 레벨이 높을수록 큰 차이는 아니지만 L*값이 증가한 것으로 나타났다. 이는 모발 시료의 바탕 레벨이 높을수 록 명도가 높아진다는 Kim (2017)와 Jang \& Park (2015)의 연 구결과와 같은 결과를 나타냈다. 또한 대조군 탈색모는 11 레벨 로 탈색하여 명도가 아주 밝은 상태이고 실험군 모발은 7,9 레벨 은 탈색이 덜 된 상태이기 때문에 대조군과 비교 시에는 실험군 의 $\mathrm{L}^{*}$ 값이 감소되었다. 대조군과 실험군의 같은 11 레벨 비교 시 백련초에 의해 염색된 실험군이 대조군인 탈색모 11 레벨보다 $\mathrm{L}^{*}$ 값이 작은 것을 알 수 있는데 이는 백련초에 의한 염착이 되어 $\mathrm{L}^{*}$ 값이 감소된 것으로 사료된다.

백련초를 도포하여 $20 \mathrm{~min}$ 열처리하고 염색한 모발의 L*값은 탈색모와 비교하여 각각의 $7,9,11$ 레벨의 모발에서 모두 L*값 은 감소하는 것을 확인할 수 있다. 그러나 $7,9,11$ 레벨을 비교 시에는 레벨이 증가할수록 $\mathrm{L}^{*}$ 값이 증가함을 확인할 수 있다. 이 와 같은 결과는 대조군 탈색모는 11 레벨로 탈색하여 명도가 아주 밝은 상태이고 실험군 모발은 7,9 레벨은 탈색이 덜 된 상태이기
때문에 대조군과 비교 시에는 실험군의 $\mathrm{L}^{*}$ 값이 감소되었다. 대조 군과 실험군의 같은 11 레벨 비교 시 백련초에 의해 염색이 된 실 험군이 대조군인 탈색모(bleach hair) 11 레벨보다 L"값이 작은 것을 알 수 있는데 이는 백련초에 의한 염착이 되어 $\mathrm{L}^{*}$ 값이 감소 된 것으로 사료된다.

\section{2) 백련초 염색모의 $a^{*}$ 측정}

백련초 분말색소를 사용하여 $10 \mathrm{~min}$ 와 $20 \mathrm{~min}$ 열처리한 모 발의 표면색상 분석 결과 $\mathrm{a}^{*}$ 값은 Table 3 , Table 4 와 같다.

백련초를 도포하여 $10 \mathrm{~min}$ 열처리한 모발의 $\mathrm{a}^{*}$ 값의 변화로 모 두 + 로 측정되었다. 대조군으로 사용된 탈색모 보다 모든 실험군 레벨에서 $\mathrm{a}^{*}$ 값이 감소하는 것으로 나타났다. 또한 실험군 레벨이 높아질수록 $\mathrm{a}^{*}$ 값이 증가하여 붉은 기가 높은 것을 알 수 있다.

백련초를 도포하여 $20 \mathrm{~min}$ 열처리한 모발의 $\mathrm{a}^{*}$ 값의 변화로 모 두 + 로 측정되었다. 대조군으로 사용된 탈색모 보다 모든 실험군 레벨에서 $\mathrm{a}^{*}$ 값이 감소하는 것으로 나타났다. 또한 실험군 레벨이 높아질수록 $\mathrm{a}^{*}$ 값이 증가하여 붉은 기가 높은 것을 알 수 있다. 이 는 탈색에 의한 멜라닌 색소 파괴로 인해 밝은 모발에 표현이 더 욱 잘 된다는 것을 알 수 있다.

\section{3) 백련초 염색모의 $b^{*}$ 측정}

백련초 분말색소를 사용하여 $10 \mathrm{~min}$ 와 $20 \mathrm{~min}$ 열처리한 모발 의 표면색상 분석 결과 $\mathrm{b}^{*}$ 값은 Table 3 , Table 4 와 같다.

백련초를 도포하여 $10 \mathrm{~min}$ 열처리한 모발의 $\mathrm{b}^{*}$ 값의 변화로 모 두 + 로 측정되었다. 대조군으로 사용된 탈색모 보다 모든 실험군 레벨에서 $b^{*}$ 값이 감소하는 것으로 나타났다. 또한 실험군 레벨이 높아질수록 $\mathrm{b}^{*}$ 값이 증가하여 황색 기가 높은 것을 알 수 있다.

백련초를 도포하여 $20 \mathrm{~min}$ 열처리한 모발의 $\mathrm{b}^{\star}$ 값의 변화로 모 두 + 로 측정되었다. 대조군으로 사용된 탈색모 보다는 모든 실험 군 레벨에서 $\mathrm{b}^{*}$ 값이 감소하는 것으로 나타났다. 또한 실험군 레벨

Table 2. Brightness $L^{*}$ value

\begin{tabular}{lcccc}
\hline Heat treatment time & Bleached hair & Virgin hair & 7 level & 9 level \\
$10 \mathrm{~min}$ & 50.58 & 17.73 & 21.47 & 33.11 \\
$20 \mathrm{~min}$ & 50.58 & 21.95 & 25.80 & 32.28 \\
\hline
\end{tabular}

Table 3. $a^{*}, b^{*}$ value

\begin{tabular}{|c|c|c|c|c|c|c|}
\hline \multirow{3}{*}{$10 \mathrm{~min}$} & & Bleached hair & Virgin hair & 7 level & 9 level & 11 level \\
\hline & $a^{*}$ & 50.58 & 1.37 & 2.37 & 10.73 & 13.06 \\
\hline & $b^{*}$ & 50.58 & 0.91 & 2.68 & 17.17 & 23.61 \\
\hline
\end{tabular}

Table 4. $a^{*}, b^{*}$ value

\begin{tabular}{ccccccc}
\hline \multirow{2}{*}{$20 \mathrm{~min}$} & Bleached hair & Virgin hair & 7 level & 9 level & 11 level \\
& $\mathrm{a}^{*}$ & 50.58 & 7.22 & 10.65 & 11.27 & 12.90 \\
& $\mathrm{~b}^{*}$ & 50.58 & 2.40 & 12.98 & 19.11 & 24.33 \\
\hline
\end{tabular}


이 높아질수록 $b^{*}$ 값이 증가하여 황색 기가 높은 것을 알 수 있다.

4) 백련초 염색모의 $L^{*}, a^{*}, b^{*}$ 측정 결과 비교

백련초 분말색소를 사용하여 $10 \mathrm{~min}$ 열처리한 모발의 표면색 상 $\mathrm{a}^{*}$ 값과 $\mathrm{b}^{*}$ 값의 결과는 Table 3 와 같다.

버진 헤어 일 때는 $a^{*}$ 값이 미비하지만 조금은 높고, 탈색레벨이 높을수록 각 시료 별로 비교하면 $\mathrm{b}^{\star}$ 값이 높다는 것을 알 수 있다. 이는 탈색에 의한 멜라닌 파괴의 결과로 사료된다.

백련초 분말색소를 사용하여 $20 \mathrm{~min}$ 열처리한 모발의 표면색 상 $\mathrm{a}^{*}$ 값과 $\mathrm{b}^{*}$ 값의 결과는 Table 4 과 같다.

버진헤어와 탈색레벨이 낮은 7레벨에서는 $\mathrm{a}^{*}$ 값이 높았지만 9 , 11 레벨 일 때는 $b^{*}$ 값이 높게 나타났다. 이는 건강모와 7레벨 같이 명도가 낮은 모발에서는 붉은 색이 잘 표현이 되고, 탈색레벨의 명도가 높을수록 황색의 표현이 잘 되기 때문인 것으로 사료된다.

백련초 분말색소를 사용하여 $10 \mathrm{~min}, 20 \mathrm{~min}$ 열처리한 모발 의 표면색상 분석 결과 $\mathrm{L}^{*}$ 값의 비교는 Table 2 와 같다.

버진헤어와 7레벨에서는 $20 \mathrm{~min}$ 열처리한 시료의 $\mathrm{L}^{*}$ 값이 높 은 것을 알 수 있고, 9 레벨과 11 레벨에서는 $10 \mathrm{~min}$ 처리 한 시료 의 L'값이 미비하게 높은 것을 알 수 있다. 이는 탈색 레벨이 낮은 버진헤어와 7레벨에서는 열처리 시간을 오래할수록 $\mathrm{L}^{*}$ 값이 증가 하고, 이미 탈색이 많이 된 레벨에서는 $\mathrm{L}^{*}$ 값이 감소함을 나타내서 탈색이 많이 된 레벨에서는 열처리를 오래할수록 염착이 더 잘 됨 을 확인할 수 있다. 이로 인해 온도가 염착력에 미치는 영향을 확 인할 수 있다.
5) 백련초 염색모의 $C^{*}$ 측정

CIELAB 표색계의 색상에서 채도는 $\mathrm{C}^{\star}$ 값으로 표현한다. '채도' 란 색의 순도에 관한 것이다(Shin \& Yun, 2014). 모발 실제 염색 에서는 채도가 염색성을 나타내기도 한다.

백련초 분말색소를 사용하여 $10 \mathrm{~min}, 20 \mathrm{~min}$ 가온 처리한 모 발의 표면색상 분석 결과 $\mathrm{C}^{\star}$ 값의 비교는 Table 5 와 같다.

$\mathrm{C}^{\star}$ 값은 $10 \mathrm{~min}$ 열처리, $20 \mathrm{~min}$ 열처리 시 모두 건강모, 7, 9, 11 레벨로 갈수록 증가하였다. 이는 염색성이 탈색레벨이 증가 할 수록 증가함을 알 수 있고, $10 \mathrm{~min}$ 열처리 시 보다는 $20 \mathrm{~min}$ 열 처리에서 근소하게 더 증가함을 확인 할 수 있다. 이는 열처리를 $10 \mathrm{~min}$ 을 더한 결과로 사료된다. 열처리 $20 \mathrm{~min}$ 일 때 채도가 증 가하였지만, 큰 차이가 아니므로 실제 시술 시에는 열처리에 의한 모발 손상을 고려하여 $10 \mathrm{~min}$ 열처리가 염색성과 모발손상을 방 지하는데 더 좋은 시술방법인 것으로 사료된다. 또한 채도가 증가 한 것은 백련초의 염색성보다는 모발 천연의 유 멜라닌 색소에 의 한 채도 값으로 사료된다.

\section{6) 백련초 염색모의 염착 농도 $\mathrm{K} / \mathrm{S}$ 측정}

백련초 분말색소를 사용하여 $10 \mathrm{~min}, 20 \mathrm{~min}$ 가온 처리한 모 발의 표면색상 분석 결과 $\mathrm{K} / \mathrm{S}$ 값의 비교는 Table 6 과 같다.

$\mathrm{K} / \mathrm{S}$ 값은 가온 $10 \mathrm{~min}$ 처리, $20 \mathrm{~min}$ 처리 시 모두 건강모, 7 , 9,11 레벨로 갈수록 감소하였다. 이는 염색성이 탈색레벨이 증가 할수록 감소함을 알 수 있었고, 가온 $10 \mathrm{~min}$ 처리 시 보다는 20 $\min$ 처리에서 근소하게 덜 감소함을 알 수 있었다. $\mathrm{K} / \mathrm{S}$ 값은 염 료의 사용량에 비례하는 값이다. 염료의 양을 동일하게 사용할 경

Table 5. $C^{*}$ value

\begin{tabular}{lcccc}
\hline Heat treatment time & Bleached hair & Virgin hair & 7 level & 9 level \\
$10 \mathrm{~min}$ & 50.58 & 1.64 & 3.58 & 20.25 \\
$20 \mathrm{~min}$ & 50.58 & 2.23 & 3.13 & 22.18 \\
\hline
\end{tabular}

Table 6. $\mathrm{K} / \mathrm{S}$ value

\begin{tabular}{|c|c|c|c|c|}
\hline Heat treatment time & Virgin hair & 7 level & 9 level & 11 level \\
\hline $10 \mathrm{~min}$ & 20.11 & 14.54 & 12.62 & 6.17 \\
\hline $20 \mathrm{~min}$ & 20.11 & 17.39 & 14.64 & 12.10 \\
\hline
\end{tabular}

Table 7. Pigment loss

(Unit: 0.D.)

\begin{tabular}{|c|c|c|c|c|c|}
\hline Experiment Data & One day & Two day & Tree day & Four day & Five day \\
\hline 11 level & 0.021 & 0.005 & 0.001 & 0.001 & 0.000 \\
\hline
\end{tabular}

O.D., optical density.

Table 8. Tensile strength value

(Unit: kgf/mm²)

\begin{tabular}{|c|c|c|c|c|c|}
\hline Heat treatment time & Bleached hair & Virgin hair & 7 level & 9 level & 11 level \\
\hline $10 \mathrm{~min}$ & 84.6 & 260.7 & 248.7 & 244.8 & 160.0 \\
\hline $20 \mathrm{~min}$ & 84.6 & 229.3 & 214.7 & 209.1 & 148.2 \\
\hline
\end{tabular}


우에는 열처리 시간에 따라 값의 차이가 나타나는데 $10 \mathrm{~min}$ 보다 $20 \mathrm{~min}$ 처리 시의 값이 조금 높은 것은 가온 처리를 $10 \mathrm{~min}$ 더 한 결과로 사료된다.

\section{2. 백련초 염색모의 물빠짐 측정}

백련초로 도포한 시료의 물 빠짐 측정결과는 Table 7과 같다. 물 빠짐은 염색소가 이온결합으로 모발에 부착되는 원리로 약 알 칼리성 반영구 염모제에 비해 모발 손상이 적은 반면 색소 손실 이 비교적 빠르다(Chae et al., 2009).

물빠짐 측정은 모든 시료를 다 측정하기 보다는 백련초 분말색 소의 염색력을 알기 위해 대표적인 시료 하나만 선택하여 측정하 였다. 시료들 중 $\mathrm{L}^{*}$ 값과 $\mathrm{a}^{*}$ 값, $\mathrm{b}^{*}$ 값을 $10 \mathrm{~min}$ 열처리와 $20 \mathrm{~min}$ 열처리한 시료를 비교하여 높은 값을 나타낸 $20 \mathrm{~min}$ 열처리한 시료를 선택하였다. 열처리 $20 \mathrm{~min}$ 한 시료 중에서도 가장 높은 값으로 측정된 11 레벨의 시료로 물빠짐을 측정하였다. 1 일차에 물빠짐이 가장 심한 것을 알 수 있었고, 2 일차부터는 급격하게 물빠짐이 감소하였고, 3 일차부터는 거의 물빠짐이 없고 5 일차에 는 완전 물빠짐이 없었다. 이는 이온결합으로 인한 염착력의 약 함과 모발손상으로 인한 염색소의 유실이 커지는 결과이고 5 일차 에 물빠짐이 없는 이유는 염색소 분자 중 큰 분자는 모표피 또는 모피질에 흡착되어 더 이상 물빠짐이 없는 것으로 사료된다.

\section{3. 백련초 염색모의 인장강도 측정 결과}

백련초로 도포한 시료의 인장강도 측정결과는 Table 8 와 같다. 인장강도 측정결과, 열처리 $10 \mathrm{~min}$ 과, $20 \mathrm{~min}$ 한 시료들 모두 탈색모 보다는 건강모와 $7,9,11$ 레벨에 백련초로 도포한 시료들 의 인장강도가 증가하였다. 이는 탈색모에 백련초 분말색소 도포 시 모질 개선 효과가 있다고 할 수 있다. 그러나 건강모의 인장강 도 보다는 7레벨에서 9 레벨로 탈색 레벨이 증가할수록 인장강도 는 감소하였다. 이는 시료의 레벨이 높을수록 탈색을 많이 한 결 과로 사료된다. 모발의 손상을 가장 많이 초래하는 탈색제에 의 해 모표피 내의 세포막복합체 유실과 함께 모피 간충물질의 유실 로 인장강도가 저하된다는 결과와 또한 모발은 화학적으로 단백 질 중의 시스틴 함량이 감소하여 물리적으로 인장강도가 감소한 다는 Oh \& Choe (2012) 결과와 동일한 결과로 나타났다.

\section{Conclusion}

본 연구는 자신의 아름다움을 표현하는 방법 중 하나인 헤어 염색에 의한 모발 손상을 줄일 수 있는 천연 염모제 성분을 개발 하고자 하였다. 천염 염모제 성분으로는 백련초 분말색소를 이용 하여 건강모, 탈색모(11레벨), $7,9,11$ 레벨의 모발 시료에 도포
한 후 열처리를 $10 \mathrm{~min}, 20 \mathrm{~min}$ 으로 다르게 처리하였다. 열처리 후 모발을 세척하여 시료 별로 염색력을 측정하고자 $\mathrm{L}^{*}, \mathrm{a}^{*}, \mathrm{~b}^{*}$ 값 과, $\mathrm{C}^{\star}$ 값과, $\mathrm{K} / \mathrm{S}$, 물빠짐 값을 비교 분석하였고, 모질의 변화를 알기 위해 인장강도를 측정하였다. 그 결과 다음과 같은 결론을 얻었다.

첫째, 염색력 측정 결과 $\mathrm{L}^{*}$ 값은 백련초 색소로 도포한 후 열처 리 $10 \mathrm{~min}, 20 \mathrm{~min}$ 한 모발시료는 모발의 레벨이 높을수록 큰 차 이는 아니지만 $\mathrm{L}^{*}$ 값이 증가한 것으로 나타났다. $\mathrm{a}^{*}$ 값은 열처리 $10 \mathrm{~min}$ 과 $20 \mathrm{~min}$ 한 모발시료는 모발의 레벨이 높을수록 큰 차 이로 $\mathrm{a}^{*}$ 값이 증가한 것으로 나타났다. $\mathrm{b}^{*}$ 값은 열처리 $10 \mathrm{~min}$ 과 $20 \mathrm{~min}$ 한 모발시료는 모발의 레벨이 높을수록 큰 차이로 $\mathrm{b}^{*}$ 값 이 증가한 것으로 나타났다. 이는 모발의 시료의 바탕 레벨이 높 을수록 적색과 황색이 잘 표현되기 때문이라 사료된다.

둘째, 염색성이 탈색레벨이 증가 할수록 감소함을 알 수 있었 고, 가온 $10 \mathrm{~min}$ 처리 시 보다는 $20 \mathrm{~min}$ 처리에서 근소하게 덜 감소함을 알 수 있었다.

셋째, $\mathrm{C}^{*}$ 값은 $10 \mathrm{~min}, 20 \mathrm{~min}$ 열처리 시 모두 건강모, 7, 9, 11 레벨로 갈수록 증가하였다.

이는 염색성이 탈색레벨이 증가 할수록 증가함을 알 수 있었 고, $10 \mathrm{~min}$ 열처리 시 보다는 $20 \mathrm{~min}$ 열처리에서 근소하게 증가 하였다. 이는 열처리를 $10 \mathrm{~min}$ 을 더한 결과로 사료된다.

넷째, 물빠짐 측정결과 1 일차에 물 빠짐이 가장 심한 것을 알 수 있었고 2 일차부터는 급격하게 물빠짐이 감소하였으며 3일차 부터는 거의 물빠짐 없고 5 일차에는 완전 물빠짐이 없었다.

다섯째, 인장강도 측정결과, $10 \mathrm{~min}$ 열처리와, $20 \mathrm{~min}$ 열처 리한 시료들 모두 탈색모 보다는 건강모와 $7,9,11$ 레벨에 백련 초로 도포한 시료들의 인장강도가 증가하여 이는 모질의 개선 효 과가 있다고 할 수 있다. 그러나 건강모의 인장강도 보다는 7레 벨에서 9 레벨로 탈색 레벨이 증가할수록 인장강도는 감소하였다.

이와 같은 결과로 향후 천연 백련초 분말색소를 사용한 천연 염색 시 적절한 열처리 시간은 $10 \mathrm{~min}$ 정도이고, 백련초의 색상 인 파스텔 색상으로 설정하면 미용 현장에서 실제 모발 염색에 활용 가능할 것으로 보이며 모질의 개선에도 효과가 있을 것으로 사료된다. 합성 염모제의 문제점을 보완할 수 있는 대안으로 천 연 염료 에 대한 연구와 개발이 활발하게 진행되고 있다. 천연염 료는 합성염료에 비해 복합 성분의 색소를 함유하므로 발색이 자 연스럽고, 변·퇴색이 일어나도 안정된 색감을 나타내며, 염색 조 건에 따라 다양한 명도와 색상을 발현할 수 있다는 장점이 있다 (Kwon et al., 2004). 추후 백련초로 염모제를 상용화 할 시에는 염색의 지속성과 색 표현에 대한 후속 연구가 필요할 것으로 생 각한다. 


\section{References}

Bai SK. The dyeing propertyies of silk fabric with Brassica campestris. Fashion \& Textile Research Journal, 7: 542546, 2005.

Chae HO, Kwan SH, Na MS. Color maintenance of colored hair using shampoo and conditioner. Journal of the Korean Society of Beauty and Art, 10: 45-62, 2009.

Cho KR. Natural dye and dying. Hyungseul, Seoul, p160, 2000.

Choi HJ. The study on the physiological activities with materials of the natural hair dye using Nandina domestica leaves. Journal of The Korean Society of Cosmetology, 21: 126-130, 2015.

Choi HJ, Jung ال Il. Evaluation of dermal bioactive properties of Opuntia humifusa (Backryeoncho) fruits fermented with Streptococcus thermophilus. Journal of The Korean Society of Cosmetology, 23: 515-520, 2017.

Jang AS, Park $\mathrm{CH}$. A study on the hair dyeing and colorfastness using extracts of mulberry. Asian Journal of Beauty and Cosmetology, 13: 237-242, 2015.

Jeong NY, Lim SN, Choi CN. Dyeability of oxidative permanent hair coloring agents and the damage of hair. Textile Coloration and Finishing, 24: 305-312, 2012.

Kim DH, Do JY. A effects of perm's pre-treatment to the mist prescribed by OFSE extract. Journal of the Korean Society of Beauty and Arts, 18: 25-38, 2017.

Kim HH, Kwon TJ. Effect of protease on the morphological properties and dyeability of human hair. Textile Coloration and Finishing, 20: 59-65, 2008.

Kim JS. Dyeing power of coating permanent to utilize a kaoliang pigment. Asian Journal of Beauty and Cosmetology, 12: 127-132, $2014 a$.

Kim JS, Lim DJ, Shin HC. Hair coloring mate. League Line, Seoul, p62, 2006.

Kim JS, Choe TB. Study on dyeing power pursuant to production of the first formulated type of acidic hairdye to utilize a kaoliang pigment. Asian Journal of Beauty and Cosmetology, 8: 201-210, 2010.
Kim JS. Hair coloring. Kuhminsa, Seoul, pp27-28, 2017.

Kim JR, Ko KS. The efficacy of Gastrodia Elata Blume (GEB) extract through chemical repetitive treatment of hair. Journal of the Korean Society of Beauty and Art, 15: 203-216, 2014.

Kim KS. Research trends relevant with hair growth promotion and scalp condition improvement by applying natural extracts. Asian Journal of Beauty and Cosmetology, 12: 17-24, 2014b.

Kim NS. Chemistry of dyeing. Gyomonsa, Seoul, p3, 1992.

Kuti JO, Galloway CM. Sugar composition and invertase activity in prickly pear fruit. Journal of Food Science, 59: 87-388, 1994.

Kwon MS, Jeon DW, Choi IR, Kim JJ. A study on natural dyeing using Caesalpinia sappan: mordanting effect of rice straw ash solution. The Research Journal of the Costume Culture, 12: 908-917, 2004.

Lee MS, Joung JS, Park DY. The effects of Arctium lappa L. root extracts on the scalp and hair. Asian Journal of Beauty and Cosmetology, 13: 43-48, 2015.

Lee YS, Rho JO. Quality characteristics of kimchi with added Backryeoncho (Opuntia ficus-indica var. saboten) extract and its acceptability by middle school students. Korean Journal of Human Ecology, 21: 1211-1222, 2012.

Moon JW, Kim KY. Change of physical properties and observation of hair cuticles' morphology in Caesalpinia sappan colored hair. Journal of the Korean Society of Beauty and Art, 16: 59-73, 2015.

Oh MS, Choe TB. Determination of hair damage index using methylene blue staining method. Journal of The Korean Society of Cosmetology, 18: 531-537, 2012.

Shin YS, Yun MK. Dyeability of the hanji-fabric by yellow natural dyestuffs. Journal Korea Design Forum, 45: 7384, 2014.

Yoo SE, Choi WJ. A study of hair dyeing using natural Gardenia (Gardenia jasminoides Ellis) yellow pigment and electrolyzed water and changes in hair color. Journal of the Korean Society of Beauty and Art, 18: 189-201, 2017. 


\section{국문초록}

\section{백련초의 모발에 대한 천연염색 원료 연구}

김주섭 ${ }^{1}$, 유세은 ${ }^{2 *}$

${ }^{1}$ 상지영서대학교 뷰티케어과, 강원도 원주시, 한국

${ }^{2}$ 여주대학교 뷰티미용과, 경기도 여주시, 한국

목적: 본 연구는 자신의 아름다움을 표현하는 방법 중 하나인 헤어 염색에 대한 논문이다. 모발 손상을 줄일 수 있는 천연 염모제 성분을 개발하고자 하였다. 방법: 천염 염모제 성분으로는 백련초 분말색소를 이용하여 건강모, 탈색모(11레벨)에 도포하였다. 또 한 탈색모 7, 9, 11레벨의 모발 시료에 백련초 분말색소를 도포한 후 방치 시간을 $10 \mathrm{~min}, 20 \mathrm{~min}$ 으로 다르게 가온 후 모발을 세척 하였다. 측정방법으로 염색력을 알기 위해 시료별로 $\mathrm{L}^{*}, \mathrm{a}^{*}, \mathrm{~b}^{*}$ 값과, $\mathrm{C}^{*}$ 값과, 물빠짐 값을 비교 분석하였고 모질의 변화를 알기 위 해 인장강도를 측정하였다. 결과: 측정 결과는 $\mathrm{L}^{*}, \mathrm{a}^{*}, \mathrm{~b}^{*}$ 값과 $\mathrm{C}^{*}$ 값은 가온처리 $10 \mathrm{~min}$ 보다 $20 \mathrm{~min}$ 일때 증가하였다. $\mathrm{K} / \mathrm{S}$ 값은 10 $\min ㅂ ㅗ ㄷ ㅏ ~ 20 \mathrm{~min}$ 일 때 증가하였다. 백련초로 도포한 시료의 인장강도는 탈색모 보다 증가하였고 물빠짐은 5 일째 측정 시 색소의 물빠짐이 없었다. $\mathrm{L}^{*}, \mathrm{a}^{*}, \mathrm{~b}^{*}$ 값과, $\mathrm{C}^{*}$ 값의 증가는 백련초가 모발에 염색이 되었다는 것을 의미하고 인장강도 증가는 백련초 염색에 의해 모질이 개선되었다는 것을 의미한다. 결론: 결론으로 백련초가 천연염색의 원료로서 사용이 가능하고, 모질의 개선에도 효과 가 있다.

핵심어: 백련초, 모발, 염색력, 변화, 모표피

\section{참고문헌}

권민수, 전동원, 최인려, 김종준. 소목 천연 염색에 관한 연구 II: 잿물의 매염효과에 대하여. 복식문화연구, $12: 908-$ 917, 2004.

김도희, 도주연. 백년초(OFSE) 추출물을 처방한 미스트의 펌 전처리 효과. 한국인체미용예술학회지, 18: 25-38, 2017. 김경숙. 천연추출물을 이용한 발모 및 두피개선에 관한 연구 동향. 아시안뷰티화장품학술지, $12: 17-24,2014$. 김노수. 染色化學. 교문사, 서울, p3, 1991.

김진란, 고경숙. 모발의 화학적 반복 시술에서 천마 추출물 효과. 한국인체미용예술학회지, 15: 203-216, 2014. 김주섭. 고량색소를 첨가한 코팅퍼머제의 염색력. 아시안뷰티화장품학술지, 12: 127-132, 2014. 김주섭, 임대진, 신홍철. 헤어컬러링메이트. 리그라인, 서울, $\mathrm{p} 62,2006$.

김주섭, 최태부. 고량색소를 첨가한 1제형 산성염모제 제조에 의한 염색력 연구. 아시안뷰티화장품학술지, 8: 201-210, 2010.

김주섭. 헤어컬러링. 구민사, 서울, pp27-28, 2017

김홍희, 권태종. 프로테아제 처리가 모발의 염색성 및 형태적 특성에 미치는 영향. 한국염색가공학회지, 20: 59-65, 2008.

문재원, 김기영. 소목으로 염색한 모발의 물리적 성상 변화와 모표피의 형태 관찰. 한국인체미용예술학회지, $16: 59-73$, 2015.

배상경. 견직물에 대한 유채의 염색성 및 항균성. 한국의류사업학회지, 7: 542-546, 2005.

이미선, 정지선, 박도영. 우엉뿌리 추출물이 두피와 모발에 미치는 영향. 아시안뷰티화장품학술지, 13: 43-48, 2015. 이영숙, 노정옥. 백련초 추출물 첨가 김치의 품질특성 및 중학교 급식에서의 수응도 평가. 한국생활과학회지, $21: 1211-$ 1222, 2012.

오명숙, 최태부. Methylene Blue 염색법을 이용한 모발손상지수의 결정. 한국미용학회지, 18: 531-537, 2012. 
유세은, 최원준. 천연치자(gardenia jasminoides Ellis) 황색소와 전해수를 이용한 모발의 염색 및 변화 연구. 한국인체미 용예술학회지, 18: 189-201, 2017.

장애선, 박철호. 오디(Mulberry) 추출물의 모발 염색 및 견뢰도 연구. 아시안뷰티화장품학술지, 13: 237-242, 2015.

조경래. 천연염료와 염색. 형설출판사, 서울, $\mathrm{p} 160,2000$.

정남영, 임순녀, 최창남. 산화형 영구염모제 종류에 따른 염색성과 모발의 손상. 한국염색가공학회지, $24: 305-212$, 2012.

신영준, 윤미경. 황색계 천연염료에 의한 한지 직물의 염색성. 한국디자인포럼, 45: 73-84, 2014.

최화정, 정주임. Streptococcus thermophilus로 발효된 백년초 발효물의 피부생리활성 평가. 한국미용학회지, 23: 515$520,2017$.

최희진. 천연모발염색 소재인 남천(Nandina domestica) 잎 추출물의 생리활성 연구. 한국미용학회지, 21: 126-130, 2015.

채희옥, 권세화, 나명석. 세정제에 따른 염색모발의 착색 및 유지. 한국인체미용예술학회지, 10: 45-62, 2009. 


\section{中文摘要}

\section{仙人掌作为毛发的天然染色原料研究}

金周䀺 ${ }^{1}$, 劉洗恩 $^{2^{*}}$

1尚志岭西大学美容学科, 江原道原州市, 韩国

2马烔州大学美容美发科, 京畿道网州市, 韩国

目的: 这项研究是一篇关于染发的论文, 它是表达其美感的方法之一。并开发一种可以减少头发损伤的天然染发 剂成分。方法: 将仙人掌（Opuntia humifusa）粉末施用于未处理和漂白的（11级）头发上。另外，将涂有粉 末状着色剂的漂白的头发 ( 7,9 和 11 级) 分别加热 $10 \mathrm{~min}$ 和 $20 \mathrm{~min}$ 。然后, 它被洗涤。为了测量染色效率, 通 过样品比较 $L^{*}, a^{*}, b^{*}, C^{*}$ 和脱色值。另外, 为了分析毛发质地的变化, 测量拉伸强度。结果: 根据测量结果, 当加热 $20 \min$ 时, $L^{\star}, a^{\star}, b^{\star}$ 和 $C^{\star}$ 值比 $10 \min$ 更多。加热 $20 \mathrm{~min}$ 后, $K / S$ 值比 10 min增加更多。涂有仙人掌的 样品的拉伸强度高于漂白的头发。在染色后,第 5 天测量样品时未观察到褪色。增加 $L^{\star}, a^{\star}, b^{\star}$ 和 $C^{\star}$ 值意味着头发 用仙人掌染色。拉伸强度的增加表明通过使用仙人掌染色改善了头发质地。结论: 因此, 仙人掌作为天然着色成 分是良好的，具有改善头发质地的良好效果。

关键词: 仙人掌, 头发, 染料能力, 变化, 角质层 